\title{
Human Resources Management of Track and Field Web Course in College Physical Education.
}

\author{
http://dx.doi.org/10.3991/ijet.v11i04.5463 \\ Weiliang Lin \\ Guangzhou University, Guangzhou, China
}

\begin{abstract}
This research aims is to improve the human resources management of track and field (T\&F) web courses and its application effects. Methods: The research methods include literature, expert interview, questionnaire survey, mathematical statistics, system settings, software editing etc. Results: The results show that Course Guidance includes basic network technical course and training, Member and Class includes effective setting of students and groups (class, grade and team), which improve the collective management mode of the course teaching activity, Student Evaluation consists of self-study, co-created resources, teaching task and practice course level, which are representative, effective certification of directors, administrators and technicians and effective management of continuous training and cocreated resources help the updating of the web course resources. Conclusion: Human resources management of T\&F web courses effectively improves the management of students, directors, chief instructors and assistants; it enhances not only the participants' teaching and evaluating organization form, but also helps administrators set courses and create resources.
\end{abstract}

Index Terms-College, physical education, Human resources, Track and field, Web course, management

\section{INTRODUCTION}

In the modern world, the direction of education and reform in advanced countries is to make students meet the requirements of the correspondent social professions, to reflect the students' dominant position in the learning process, to project the actual demand of the major to the knowledge system design of the web course [1]. The web course management system of basic computer course are reflected in the management mode of class management, on-line and off-line teaching management, on-line test, assignment assigning and correcting [13]. For instance, a research on the factor of chief instructor in the English web course in universities emphasizes the importance of the teachers' guidance and teaching organization [10]; the scientific management of resources and human power in industrial and academic vocational education helps improve its comprehensive development [4] $\square$ in the management of the materials of basic web courses, the administrator's collection and editing makes the course's resources more accessible [7]. Open management of web course video resources puts forward the comparative application study of web course video resource at home and abroad [2]. Functional module of the management system of Net -Course $\square$ includes the construction and management of student-teacher video area [6]. My Answering includes asking and answering questions between teachers and students and answer upload; the participants of the activities consist of teachers, students, technicians, management personnel [5].

In the role and authority management of web course construction platform, the design of teachers' and students' access to the course and the definition and application form of different roles help the management of course teaching [11]. The design and realization of web course roles include the definition of resource operating authorization and the relation description between the roles. The authorization of the roles (teacher and student), operating authorization of optimization of system resources, the markings indicating the user property and the user group with safety authority improve the user management [15]. The effective organization form of student, teacher and administrator in the resource management further enhance the sustainable development of the teaching activity in the resource module [16].

The chief instructors are part-time remote education teachers, on the basis of the ideal management mode, nanny management mode and escorting management mode, the web course developing quality is improved through the integration and the support of resource learning of escorting management mode [17]. The management of web course has the team cooperation spirit, scientific knowledge, theoretical knowledge of teaching design, answering skills, teaching evaluation skills, feedback skills and the teaching design skills of web-based teaching system [18]. The Distance Education Resource Construction Technical Standards Committee of Education Ministry of China put forward the "the web course is a certain subject's teaching content and teaching activities performed on the web, and it's the teaching goal, teaching outline, teaching strategies are organized together to generate a new form of education." [3].

Currently, the research on the relevant theoretical system of T\&F web course is mainly reflected in the following respects: The design mode of web course of $T \& F$ in physical education[12] $\square$ the basic attributes[8], the course content[9], the course parameters, the class and members, the settings of $\mathrm{T} \& \mathrm{~F}$ assignment database include the settings of test library and test management, teacher-student forum management, T\&F course introduction, T\&F reference materials, which have been in-depth studied and applied in practice[14]. However, there is a lack of literature for human resources management of T\&F web courses, so the in-depth and comprehensive study on human resources management mode of T\&F web courses, such as student course guidance, class member management, student evaluation management, teacher(administrator) web course skill management, network technician management and organizing teams to co-create resources which will help improve the student, class member, stu- 
dent evaluation and administrator of track and field web course, which has some practical significance.

\section{Study OBjects And Methodology}

\section{A. Study objects}

Take the web course of T\&F in Guangzhou university as a case, study the human resources management of track and field web course in college physical education.

\section{B. Methods}

Search for the cases of college web course human resources management at home and abroad over the years, particularly the references on the learning guidance, member and class, students' assessment, the teacher's skills of web course, the creative resources together, technician in college T\&F web course. Search in the authoritative journals related to the learning guidance, member and class, students' assessment, the teacher's skills of web course, the creative resources together, technician to lay a basis for this web course's human resources management and maintenance.

Interview: Further collect comments and suggestions from experts and professors from the network center and School of Physical Education in Guangzhou University; analyze the comprehensive construction distributions of learning guidance, member and class, students' assessment, the teacher's skills of web course, the creative resources together in the web course human resources management to make sure the effectiveness of the course's human resources management.

Questionnaire survey: On April 18, 2015, 370 shares of questionnaires referring to the $\mathrm{T} \& \mathrm{~F}$ network course, which had been handed out to 30 experts and 340 students (the students of each grade is 45 people in physical education, a total of 180 students; the students of each grade is 40 people in social sports, a total of 160 students) with random sampling methods in the network center and in $\mathrm{T} \& \mathrm{~F}$ teaching field in Guangzhou University. All questionnaires were withdrawn, and the withdrawal rate is $100 \%$.

A. Validity Test of Questionnaires: Delphi Method is adopted in this research and 20 experts are asked to assess the questionnaires in the aspects of "content validity" and "structure validity" to guarantee the validity and reliability of the questionnaires; The result shows that 10 of the experts believe that the effect of the questionnaires content is very high, 8 think it is high, 2 give an evaluation of average; 11 of the experts' evaluation is very high to the structure validity, 8 high, 1 average; no one thinks it low or very low. Generally, the questionnaires have high validity and meet the requirements of the research project.

B. Reliability Test of Questionnaires: In order to improve the stability of the questionnaires, the accuracy of the assessment should be stable and unanimous. Small sample retest method is adopted in the reliability test of questionnaires, a small number of samples are drawn from the total samples as the objects of the second test which is carried out in 15 days, the test correlation index $r=0.801$, which is high in questionnaire reliability.

The mathematical statistics: Use SPSS 16.0 statistical software to account the 370 shares questionnaires about the effects of teaching management of its network course from the experts and students of the network center and class teaching in Guangzhou University, it provides empirical evidence for the study.

System Design Method: Determine the functions of the course's teaching modules and their organic combination according to the learning theories, the teaching requirements and the logical relationship between the content and resources of teaching to improve the actual application effects.

Software programming method: According to the web course designing requirements of Specifications of Modern Remote Resource Design Technique, which was carried out by Ministry of Education in 2000, this platform is developed with soft wares, such as flash, premiere and WCB course ware making tool produced through the cooperation between Guangzhou University and Nanjing Qiaomu Science and Technology Ltd.

\section{Human Resources Management Mode OF WEB COURSES}

\section{A. Student Course Guidance Management}

On the network course training platform held by Network Center, students can learn the course's operating functions, communicate with the technicians in real-time or non-real-time and deal with the problems in links, network signals, download addresses and operating process and etc. At the beginning of the new semester, the chief instructor (director, assistant) gives course guidance to students in the aspects of course module classification, function application, network teaching material, and the content, progress and test form of teaching practice, which is to help realize the teaching task, help student study by themselves, motivate students' initiatives and improve their cognitive level of theoretical system. The on line tasks are to be finished according to teaching goals in different stages, such as assignments, tests and forum; students participate jointly in the construction and assessment of track and field web course resources.

\section{B. Class Member Management}

The class member management is classified into groups according to the factors of learning level, interest, locations, and manages the modules of assignment, test and forum. It also includes student information form in EXCEL, member adding, authorizing and management of classes in effective period of time.

In web course setting, administrator enters course member list through member management, and perform the settings of students, chief instructors, assistant teacher, browser and registered users. The number $(10,20,50,75,100)$ of items displayed per page can be adjusted; query can be performed by selecting (select from the system automatically) the conditions of member number, name, enable or not, school; then the management can be carried out in the aspect of the member's role (student, chief instructor, assistant teacher, browser, registered user), start time, state (enabled or not), operation (disabled, edit, delete).

Click Excel to import students in bulk, set the start time, select the date(yyyy-mm-dd) in the dialog box, templates (Excel template) can be downloaded, and then fill out the blanks with student user name, student number, gender, school, ID number, email address, class number and class name, and save them to a certain file. Click 
"browse" to query file and confirm upload and complete bulk importing students.

Select one or more students in the system user list to set the start and ending dates for students, click "add" to finish the operation. The user roles (student, teacher or other) can be selected; schools (click "system school" in dialog box and select School of Physical Education) can be selected; click "query", the users' number, user name and user type will be displayed, tick the user and click "add" to add the student; the specific conditions such as user number and user name can be entered to query or query all to finish adding students.

To add a new student, first is login information: name, password (at least 6 figures, without characters like $<>\& \% \#)$, password question and answer; second is basic information: real name, student number, school (School of Physical Education), birth date, gender, ID type (ID card, military card); third is course member information: start date and ending date; fourth is contact information: email address, mobile phone number, telephone number, MSN, QQ number and postal address. Submit to finish the operation.

Set start and ending dates in bulk: select date/time in the dialog box and set the validated time in the web page dialog box; delete in bulk: select the users in the list and perform delete in bulk; the setting mode of chief instructor, assistant teacher, browser and registered user and the effective setting of student type help improve the class management.

Edit: modify class property (class name and status); student management: browse student information, query and screen students, and operations such as add, modify, delete and delete in bulk are available. There also provides functions such as import from courses, import from system, import from Excel, add new user, delete in bulk and return and etc. Administrator: users can add administrator and delete records in bulk (Figure 1).

Teaching activity and task are performed in the form of classes, teams and grades, and effective member list are decided according to teaching content, task scale and form, goal and effect intention: first, class-based $T \& F$ theory teaching, or $\mathrm{T} \& \mathrm{~F}$ comprehensive practical ability test, online timed test, discussion and group PPT study; second, team-based teaching activity. aiming at supporting innovative teams in practical teaching, teacher organizes 5-8 students as a teaching presentation team, evaluates students' cooperation and individual performance according to their topics and problems; third, a large group based teaching, where brief self-evaluation and evaluating each other are suitable (Figure 1).

\section{Student Evaluation Management}

(1) Evaluation system management of teacher-student forum module: student's daily performance in practical teaching, teaching ability and student's effectiveness in cocreating resource outside class can be evaluated through the member class setting in the forum module; all these activities will be evaluated in the forum module, which includes the setting of new questions, question and answer, uploading and saving valuable questions.

Practical teaching assessment indicators are evaluated in the on-line course, such as daily evaluation, teaching evaluation and resource contribution evaluation of extracurricular practice. Daily evaluation includes attendance, daily performance(cooperation, exercises on class, instructing attitude and professional dedication); teaching evaluation includes evaluation of the contents of leading warming up, presentation of teaching plan and micro class, which is classified into 3 types: first, all students, along with the teacher, grade every student, the final score depends upon both grades; second, 5-8 students as a team (according to the teaching content), and gives a short teaching simulation successively, and are discussed and evaluated in the forum according to the time period set by the chief instructor; third, simulate practical skill teaching course(the forms of team and the whole class take turns), evaluator evaluates team members or all students in the class, the teacher gives comprehensive evaluations. Management form: the evaluation records of activities during the teaching process in the forum.

Extracurricular practice resources assessment: the resources include extracurricular T\&F training, competition, refereeing, internship, scientific research and the awards acquired and paper published during the practice experience (certificates, files and papers can contribute to the construction of the web course's resources).

(2) Evaluation System Management of Students' SelfDirected Learning and Teaching Task. Teaching statistics module can be entered through Teaching Management, and it includes teacher's spent time on-line, the progress of the courses management by the teacher, teacher's work load and teaching results.

Directory: In My teaching results displays class name, assignments finished, average score and best score of assignments marked, tests finished and average score of test marked; the current page can be printed in the Excel form to further compare the numbers of assignments, distribution of assignments, numbers of tests, average scores of tests and best scores among different classes. In the same way, statistics can be conducted to the progress of all courses or work load (Figure 2).

Click class name(Team 1, PE Class 2014) to enter statistical table of teaching results, that is, all the students' names in the class course, assignments finished, average

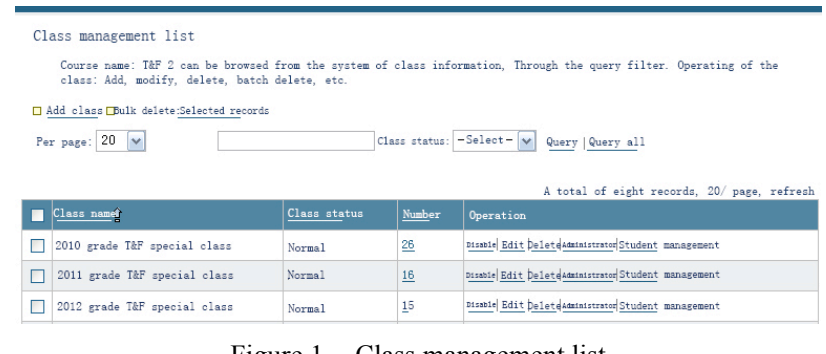

Figure 1. Class management list

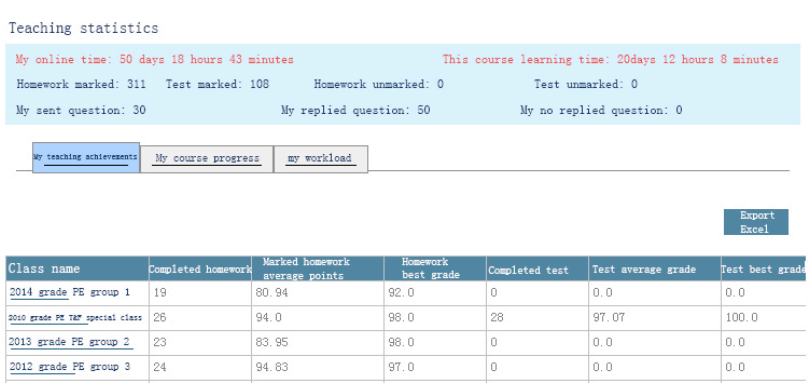

Figure 2. Teaching statistics. 
score and best score of assignments marked, tests finished, average score of test marked and on-line time; courses of other classes can also be queried, such as the required course of PE Class 2012, required course of SP Class 2012, Special Event Class 2010; click "export Excel" to export the assignments and statistical table of the class(Figure 2).

In the Export Excel Table displays student name, assignments finished, average score and best score of assignments marked, tests finished, average score and best score of test marked and on-line time.

Click a certain student's name to enter module list, which includes on-line time (total on-line learning time, total course learning time, this course's learning time), study results (assignments finished, average score and best score of assignments marked, tests finished, average score and best score of test marked), study progress(assignments unfinished, test unfinished, my questions, my answers, questions unanswered), time(H:M) and number of items(Figure 3).

\section{Teacher(administrator) Web Course Skill Management}

Teacher includes course director, chief instructor and assistant, who are supposed to provide network course skill training, which is mainly realized by the basic computer skill course and required network course for teacher retraining held by the technicians from the school's Network Center. The course director should be qualified (years of teaching experience of track and field required course, elective course and minor course) and has certificate for network course skill application; director gives advice to chief instructors and assistants on the construction and implement of the network course.

Director: the director should be an expert that has years of experience of T\&F teaching and practicing in teaching guidance, training, competition, refereeing, scientific research in $\mathrm{T} \& \mathrm{~F}$ in secondary and primary schools, and has excellent achievements in the field and has basic teaching practice and web course skills, and are able to propose new $\mathrm{T} \& \mathrm{~F}$ teaching philosophy and integrate network resources to improve the current shortcomings in practical teaching, so as to meet the reform requirement of course teaching. Course director plans the content classification of the web course and the setting of the module's teaching tasks, and organize chief instructors and administrators to explain the layout and development tendency of the course; the chief instructor or an assistant teacher should incessantly collect related materials about the teaching tasks, get very familiar with the teaching tasks' arrangement and evaluation, collect advice and suggestions and improve the teaching efficiency of the web course. Chief instructors and assistants should have Web Course Skill Application Design Qualification Certificate, and receive the web course skill training and teacher web course skill retaining held by the school.

Assistant teachers are from students (3-5), who are arranged by the director to discuss the collected materials (provided by students or chief instructors), and the selected resources are classified and uploaded to the web course assistant teachers also assist chief instructors to collect cases, files, electronic books and literature and deal with the problems which occur during the teaching process; assistant teachers are under the direct leadership of the director.

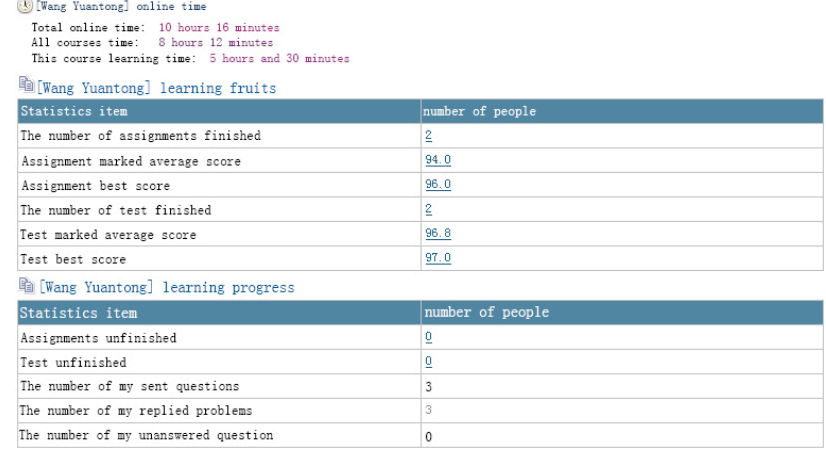

Figure 3. Student's results export list

\section{E. Organization of Team in Participation of Resource Co-Creating Management}

The teaching team includes students, teachers (director, administrator, chief instructor), assistant teacher, technician and educational administration personnel; students are the main body of study as well as the experiencer of the practical application, their participation can verify the effectiveness of the teaching activity and their cases are vivid examples, which can help the understanding of the theories and even evoke thinking of educators. Students, as the future educators, should have the ability of cases collecting and analyzing. So the participation of students has double meaning. As physical education majors, the students are required to get a command of track and field course event skills and simulate teaching skills, movement demonstration and have abilities of explaining and analyzing. The activities such as extracurricular training, refereeing, competition, scientific research and culture can improve students' ability of searching for representative topics to contribute to web course resources, which shows the problems and solution in practical application. The collected materials can be submitted in the form of pictures, texts or videos, which will be reviewed by the teachers and then set as teaching materials for the web course, which helps to develop students' ability of collecting innovative resources and editing them, and evoke them to think about the teaching.

The teacher, as the first person responsible for teaching, his or her class teaching mode should be epoch making, adapt to the requirements of the modern society and have profound and lasting guidance effect to practical application, and the discovery and collection of resources are forward looking and open-eyed; it is easier for teacher to spot students' weak points and shortcomings during the teaching process of training, refereeing, competition and scientific research, such as the teaching characteristics, training mode, sports meeting organization form and qualities needed in the practical teaching of secondary and primary T\&F teaching. During the teaching, students and teachers are regularly organized to collect and edit materials and upload them as web course resources.

The technician should be professional in computer field who are competent to develop the network platform and provide basic technical instructions, guide the setting management of the web course platform, maintain its stability and proceed its modernized information construction. Teachers may ask technicians for help or to cooperate in building the web course when they come across technical network problems, especially in making motion pictures, transforming video materials to network format, 
selecting module background, color, picture and text to enhance the visual effect when students are studying the web course.

Educational administration personnel are responsible for the qualification examination of course directors, the assessment and funding of the web course's early stage construction and organizing expert to examine the web course annually, which includes its background management skill level (technician's responsibility), effectiveness evaluation of teacher's participation in course construction and teaching application. The courses that are disqualified will be cancelled and that are not efficient or effective will be required to revise; while the courses that are qualified or excellent will be granted different amount of financial aid to optimize the web course and improve its application effect. The educational administration personnel are supposed to balance the web course construction plans of all the disciplines in the school, optimize the disciplines' network resource construction strategy(avoiding unnecessary course repetition and canceling disqualified courses), organize relevant experts to assess web course applicants' qualifications and the course module's construction effectiveness, and make differentiation funding plans for different courses, which are conducive to quality supervision of the courses, and the human power and funding aid for the courses.

\section{F. Network Technician Staff Management}

Teachers and students have access to network skill training-IT Fundamentals in the network technology course platform, which includes teacher introduction, course introduction, references, courseware download address, course contents, teacher-student interaction. Teacher introduction consists of basic information(name, education background, research direction, teaching tasks and achievements); course introduction includes content directory, course purpose and development trend; In the user course home page sets course notice platform, which provides courseware downloads, background resources links(Notice on the opening of "Network teaching resources of National Higher Education Institutions"-file: introduction and guidance), explanation of frequently asked questions(the login ID of course center and password hint) and notice of annual inspection and evaluation.

My Course(T\&F 2, Teacher Educational Skill Training - Information Technology Training: teacher-Hu Ying, school- Experiment Center, Network and Modern Education Skill Center, operation: students and relevant courses); Click Student or Relevant Courses in Operation, enter "Teacher Educational Skill Training - Information Technology Training", which displays teacher introduction(chief instructor's basic information), course introduction(basic computer introduction, basic network introduction, basic Office introduction; this module includes basic computer knowledge, Windows operating system, user security management and system optimization), references(literature, websites, books and files), school courseware download address(downloading of computer basics courseware, computer web course, Office application basics courseware), course contents(Excel 2003, Word 2003, computer management, file and folder, user security management, share of network resources, Internet application), teacher-student interaction(students, teachers and administrators communicate with technicians on the platform to solve problems in the practice of web course).
Courses can be queried in this module with the query condition of "course teacher" and etc. or query all course. Different courses in different disciplines can also be viewed and items displayed in each page $(10,20,50,75,100)$ can be set.

When a new round of evaluation policy is introduced, its specific requirements, evaluation indicators and implementation plan will be listed in the notice module by the technician; when a new special teaching module is added, its content, function and setting principle should be introduced so that the director can carry out correspondent teaching task according to the characteristic resources of the course, so as to improve the learning effectiveness of this module; downloading of new softwares and their introduction improve the software support of the web course, which is convenient for teachers and students to download materials from the web site.

In the training and technical module, there are the technician's office telephone number and mobile number, which can help teachers and students get in touch with the relevant technician any time when technical problems need to be solved so as to guarantee the normal proceeding of the web course. Technicians have the authority to access the course and use and query on relevant data, which is conducive to the reasonable and legal use guidance of the resources. The technician is also one of the organizers and experts of the web course evaluation work, one of maintainers of the platform data.

\section{RESUlts AND ANALYSIS}

\section{A. The Effectiveness of Students Course Guidance}

Figure 4 shows that $50 \%$ of the experts believe that the effect of the students course guidance is very notability, $40 \%$ think it is notability, $10 \%$ give an evaluation of average; $50.89 \%$ of the students' evaluation is very notability, $44.41 \%$ notability, $4.70 \%$ average; no one thinks it not notability. Overall, with the basic computer skill training held by the network center, students get a good understanding of the application of basic network technology, and are able to take full advantage of the software download website address provided by the course and get command of the saving, browsing, search and reapplication of the web course. Students can also get a good understanding of the overall planning of the web course and get to know how to use resource modules with software and how to solve common problems when studying the

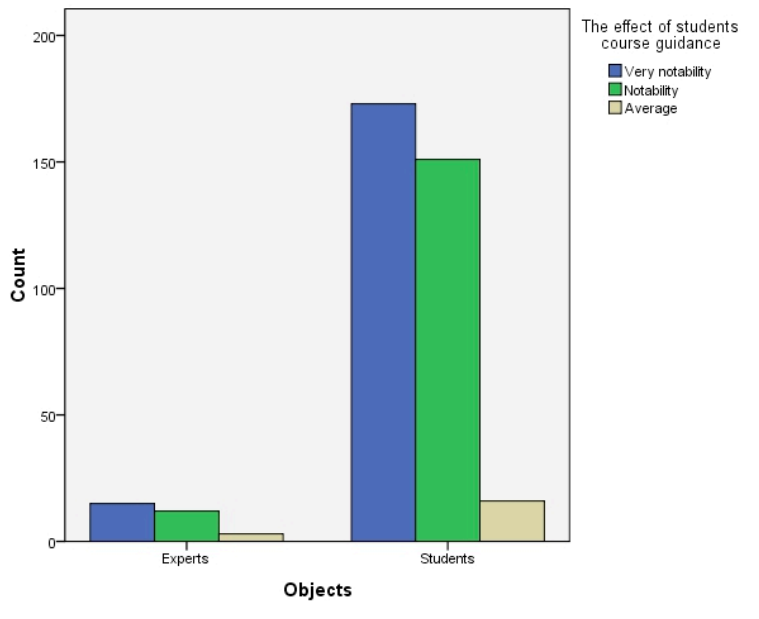

Figure 4. Students course guidance. 
web course; in the teacher-student forum, network questions can be asked and discussed in real-time or non-realtime, which improves students' basic network skills.

Students receive regular $\mathrm{T} \& \mathrm{~F}$ web course training organized by chief instructors, directors and administrators, that is, on the premise of students getting command of basic network skills, getting students know well of the structure of the knowledge module(course property, content, home page, teaching activity, practice guidance, personal information and my notes), improving their selflearning ability of the course's development trend and other course resources, giving full play to the web course's practicability and innovativeness.

A good guidance of web course teaching activity which includes assignments, tests and forum and their implementing time, form and evaluation according to the teaching contents and progress during the process of $T \& F$ teaching is conducive to student's adapting to the theory and practice mode of the web course and systematically studying of T\&F theoretical system.

\section{B. Member Class Management Effectiveness}

The figure 5 shows that $43.33 \%$ of the experts believe that the effect of the member and class management is very effective, $26.67 \%$ think it effective, $30 \%$ give an evaluation of average; $47.65 \%$ of the students' evaluation is very effective, $46.76 \%$ effective, $5.59 \%$ average; no one thinks of the effect invalid. Generally, the modular setting and update of member and class is an effective guidance for the users to manage students' basic information(name, student number, class, email address, phone number); the number of a group is decided according to the practical teaching requirement of the track and field teaching task and is added in bulk or individually in the class module to form a class, a team or a grade, which is convenient for the authorization of the group in the activities such as doing assignments, tests or forum and the evaluation system of teaching effectiveness.

The number of students taking part in track and field web course teaching (one class as a unit) is about 30 ; teacher may arrange student to have discussion to deal with class affairs or have timed on-line test according to the teaching progress.

As for assisting innovative team activities, take 5-8 students as a unit to proceed presentation of teaching plan exercise, and teaching activities are implemented according to periods and special topics, and teachers organize students to have analysis and evaluations of the teaching topics, presentation of teaching plan, teaching content, language expression and class organization.

The number of students in a grade is $60-120$, which is suitable for brief self- evaluation, evaluating others and grade affairs meeting, or unified on-line timed test of the semester, such as Level II(III) test of T\&F Referee, T\&F theory test.

\section{Student Evaluation Management Effectiveness}

Figure 6 shows that $26.67 \%$ of the experts believe that the effect of the students' assessment management is very reasonable, $50 \%$ think it is reasonable, $23.33 \%$ give an evaluation of average; $43.53 \%$ of the students' evaluation is very reasonable, $50.59 \%$ reasonable, $5.88 \%$ average; no one thinks it not reasonable. Overall, Student evaluation system are classified as this web course's modular evaluation indicators and teaching practice activity evaluation in-

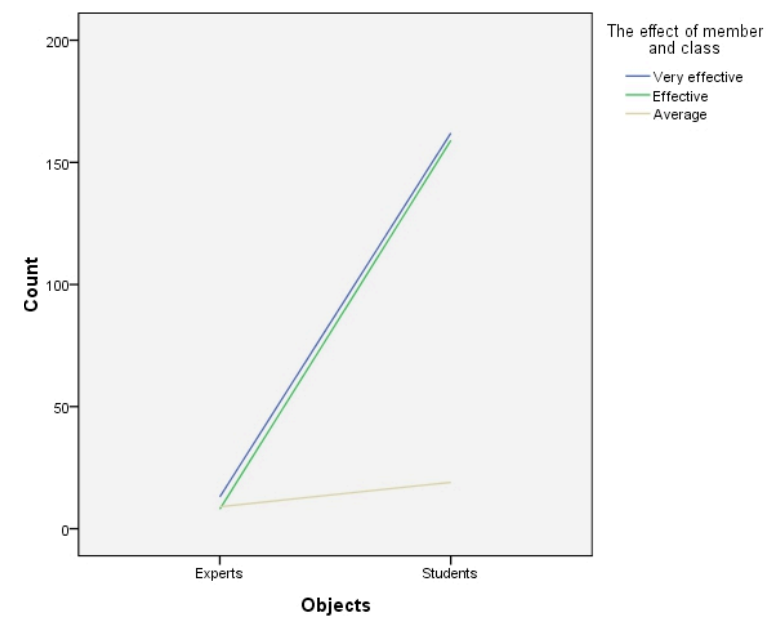

Figure 5. The effect of class and member.

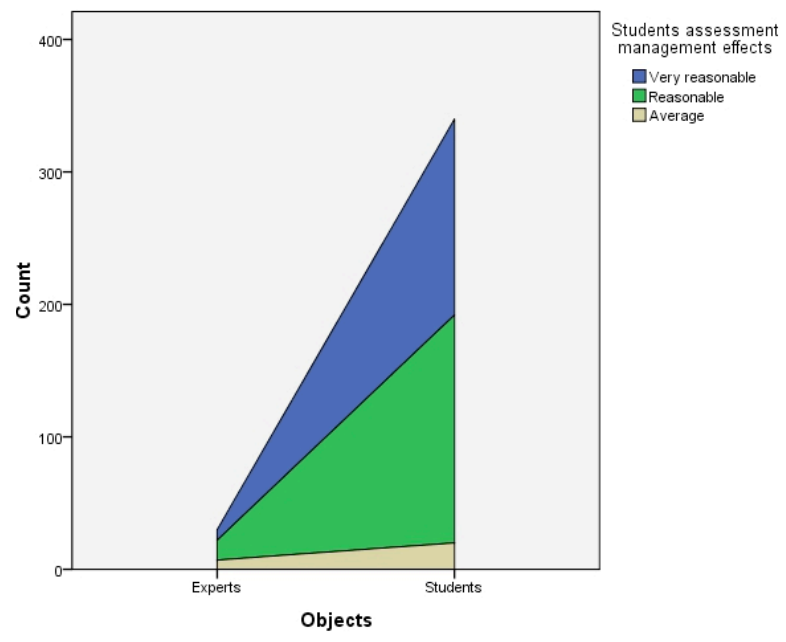

Figure 6. Students assessment management.

dicators, which forms a comparatively systematic teaching process and final evaluation system. Web course modular management mainly records students' time spent on selflearning the course, the effectiveness evaluation of teaching activity includes the class's assignments and tests finished, average score and best score, which can be exported in Excel form and which is convenient for comparative analysis: click a certain class to enter statistical table of teaching results, user can query on the class's assignments finished, average score of assignments marked, best score of the assignments, tests finished, average score of tests marked, the best score of test marked, on-line time and etc. Click on a certain student and there records the student's total on-line time, total learning time of all courses, learning time of this course, learning result and progress(assignment unfinished, test unfinished, my questions, my answers and my unanswered questions), which can systematically evaluate the student's time spent on learning the course; the effectiveness evaluation of selfexercise and assignment and the self-test and on-line timed test can improve the diversity of evaluation of the student's teaching progress and his or her command level of the knowledge, which is objective and effective.

Teacher-student forum module evaluation system management can effectively evaluate the performance of students and classes. With the process and summative evaluation of practice course, it reflects the warming up, presentation of teaching plan teaching, course teaching, 
extracurricular (training, competition, referee, practice and scientific research) co-creating web course resources, stimulates students to probe into representative teaching topics and strive to make them web course resources, which is a credit adding point of student innovative resources.

\section{Teacher(Administrator) Web Course Skill Management Effectiveness}

The figure 7 shows that $43.33 \%$ of the experts believe that the effect of teachers' network curriculum skills management is very comprehensive, $30 \%$ think it comprehensive, $26.67 \%$ give an evaluation of average; $48.53 \%$ of the students' evaluation is very comprehensive, $43.53 \%$ comprehensive, $7.94 \%$ average; no one thinks it invalid. Generally, director is responsible for checking if the teachers of the web course have network management qualification certificate and basic network course skill application qualification certificate; regular training must be implemented, such as introducing web courses, knowledge application scope of different modules and co-creating resource management, to further enhance the teachers' understanding of the web course's layout, development trend and responsibilities, which is conducive for teachers to set teaching tasks directly as administrator, guide students to take part in the web course and co-create teaching resources and enrich the web course's resources.

Teachers have self-directed learning of network technology application, network software and address of downloading software in the basic skill training held by the network center, and questions can be dealt with through real-time or non-real-time communication in the teacher-student forum, which provides a special consultation and learning platform.

Director, chief instructor, administrator and assistant teacher should have web course skill application qualification certificate and be capable of performing track and field course management, and frequently join the web course training held by the school's office of teaching affairs or network center, and fulfill the tasks of taking part in the network skill training program, which guarantees the qualification and competence of the teachers and administrators.

\section{E. Effectiveness of organizing teams to co-create resources}

Figure 8 shows that $46.66 \%$ of the experts believe that the effect of the organizing group to take part in created resources together is very reasonable, $26.67 \%$ think it is reasonable, $26.67 \%$ give an evaluation of average; $49.71 \%$ of the students' evaluation is very reasonable, $40.88 \%$ reasonable, $9.41 \%$ average; no one thinks it not reasonable. Overall, the team members include director, chief instructor, assistant teacher and technician. The director is responsible for the reasonable planning of the web course and organizing other course participants to consciously collect and compile proper and meaningful materials in the scope of their responsibility and teaching, such as movement demonstration, class organization form, terminology expressing, observation and analysis of application process, extracurricular training, refereeing, competition, scientific research and practice; meanwhile, problems in practice, solutions, talents cultivation orientation, social requirements for $\mathrm{T} \& \mathrm{~F}$ talents are added as new teaching materials of the web course to make up the monotonicity

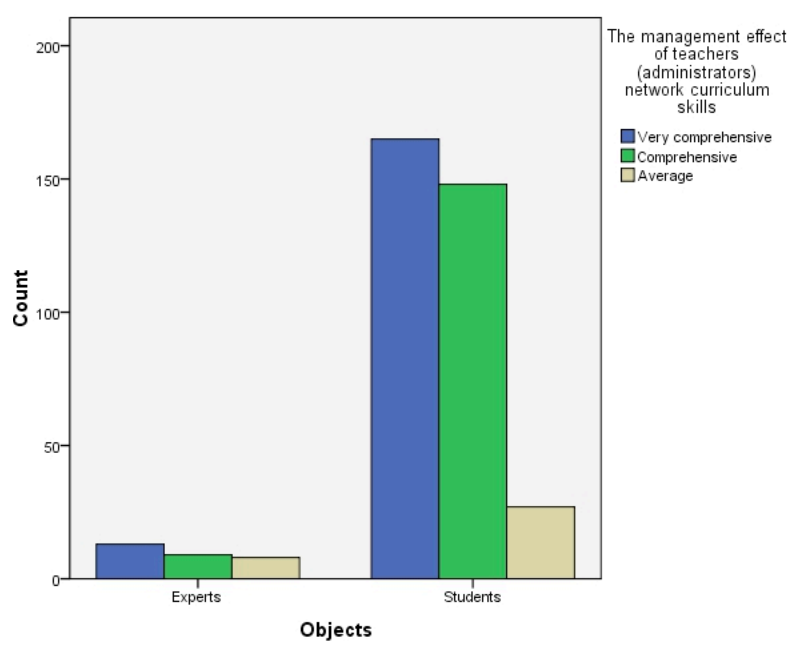

Figure 7. Teachers network course skills management.

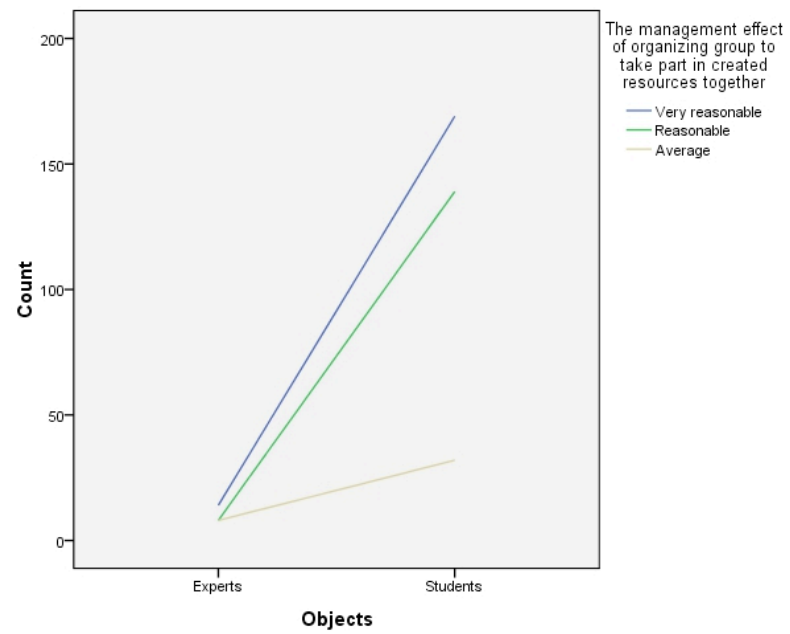

Figure 8. Organizing group to participating course resources creating.

of the traditional textbooks to create a comprehensive web course resources, so as to form a special and sustainable resource module. Assistant teacher helps director and chief instructor further edit and save already collected materials, set them in network modular format and upload them regularly, which is convenient for students to learn by themselves and for teachers to organize on-line teaching activities.

Technicians are responsible for solving technical problems occur during the management process and maintaining the normal operation of web course platform links and software applications.

\section{F. Network Technician Management Effectiveness}

Figure 9 shows that $40 \%$ of the experts believe that the effect of the network technician management is very notability, $36.67 \%$ think it is notability, $23.33 \%$ give an evaluation of average; $50 \%$ of the students' evaluation is very notability, $42.94 \%$ notability, $7.06 \%$ average; no one thinks it not notability. Generally, Technicians can provide basic network training course and technical support for the construction and maintenance of the web course and even provide instructions face to face. In the teacherstudent communication platform, administrator and technician can have question and answer interact in real-time and non-real-time, which improves technical support effectiveness; the technician optimizes innovative tools of 


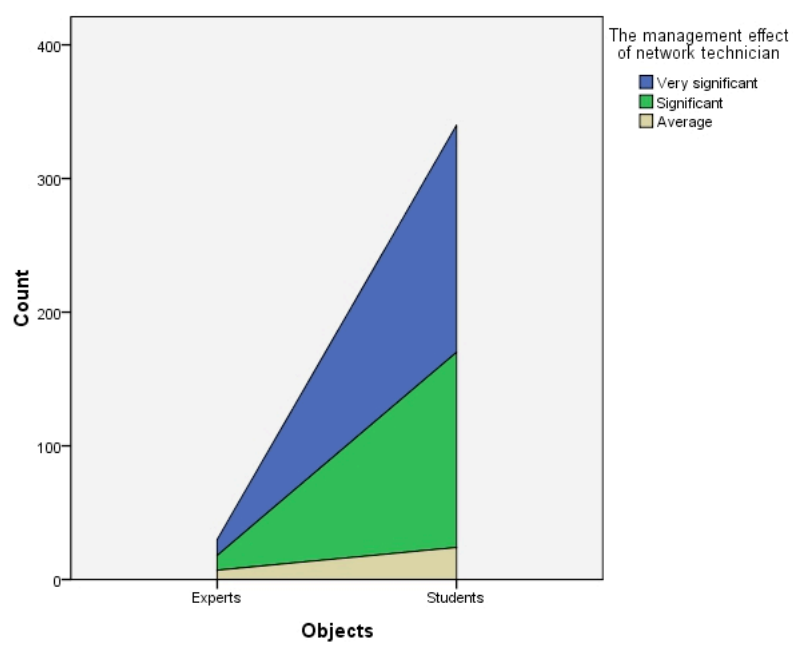

Figure 9. Network technician management

the course in real-time and helps administrator improve his or her network resource designing level and the visual effect of the resources; technician provides web course skill application training opportunity, which helps teachers and assistants improve their network skills and guarantee the construction effect of the web course; technician is also responsible for delivering notices from office of teaching affairs, helping director, chief instructor and assistant collect the result data of the course(on-line time, adding new resources, performance of teaching, evaluation effectiveness), and technician also takes part in the annual evaluation and assessment of the web courses.

\section{CONCLUSION}

The T\&F web course's human resources management includes resources of student user, member and class, student evaluation, teacher(administrator), network technician, team participating in co-creating resources, which reflect modular content setting, optimization of resources of teaching task and teaching activity; the resource modules have essential characteristics, rich in content, interactive between modules, co-creating course resources and incessant updating, which improve the web course's inventiveness and representativeness; and the function of each module is diverse, convenient to operate and has the function of guidance, which is conducive to the integration and organization of $\mathrm{T} \& \mathrm{~F}$ teaching activity resources. This study is applicable to the students majoring in physical education and to the human resources management of T\&F web course.

\section{ACKNOWLEDGMENTS}

This paper is one of the phased results of construction of track and field web course of Guangzhou university (Code: 0L1009322) and evaluation system of track and field web course of department of physical education (Code: G17), which is a 2010- present campus special research program funded by Guangzhou university and a 2015 education evaluation project funded of Guangdong assessment association. Meanwhile, please allow me to express my gratitude to Guangzhou University, it was their help especially the T\&F teachers of school of physical education and sports science and other the related students in research team, that made sure this research can be carried out successfully.

\section{REFERENCES}

[1] Cai, X., "Network vocational training design based on engagement theory", China Audio Visual Education, vol. 6, no. 3, pp. 6-9, 2009.

[2] Chen, L., Li, S., \& Ma, X. Y., "Research on the classification and demand of China's distance education practitioner", China Distance Education, vol. 11, PP. 27-30, 2004.

[3] Christian Nagel, Bill Evjen, Jay Glynn. C\#Advanced programming, 4th edition. Beijing $\square$ Tsinghua University Press $\square 2006$.

[4] Fang Xiaodong, "System of educational resource management for vocational education based on industrial culture", China distance education, vol. 1, PP. 61-63, 2013.

[5] LiJun, Yu Ping, "Analysis and Functional module of the management system of Net -Course," Journal of Jingdezhen college, vol.21, no.2, pp.41-42, 2006.

[6] Liu Tao, Wang Suli, Feng Jianwen, Zeng Qiao Lian, "The construction of network course management system based on basic computer course," Software Guide, vol. 9, no. 5, 142-143, 2010.

[7] Luo Shaoke, Sun Zhongjin, "Research on Video Courses Resources Management of Open Network Course," Popular Science \& technology, vol. 4, no.4, pp.159-160, 2009.

[8] [8] Ruan Guo-long, Liu Feng, "Discussion on the mode of managing web-based course based on material", Journal of Xianning College, vol. 24, pp. 48-53, 2004.

[9] Wang Hong-Yu., "Design of medical college network resource management system", Database and Information Management, vol. 6, no.10, pp. 45-47, 2014.

[10] Weiliang Lin, "Research on the design mode of web course of track \& field in physical education in college," International Journal of Emerging Technologies in Learning, vol.9, no.3, pp.68-72, 2014. http://dx.doi.org/10.3991/ijet.v9i3.3285

[11] Weiliang Lin, "Research on university track and field web course's basic attributes columns," International Journal of Emerging Technologies in Learning, vol.4, no.8, pp.27-33, 2013. http://dx.doi.org/10.3991/ijet.v8i4.2941

[12] Weiliang Lin, "Track and field online curricula evaluation system design for universities physical education," International Journal of Emerging Technologies in Learning, vol.4, no. 8, pp.10-16, 2013. http://dx.doi.org/10.3991/ijet.v8i4.2940

[13] Weiliang Lin, "Research on university track and field web course's basic attributes columns," International Journal of Emerging Technologies in Learning, vol.4, no.8, pp.27-33, 2013. http://dx.doi.org/10.3991/ijet.v8i4.2941

[14] Wu Ming-jun., "Study on the teacher factors in the management of web course for college English", Sino-US English Teaching, vol. 4, no.8, pp. 8-10, 2007.

[15] Yan Hanbing, Liu Mingzhuo., "Research on master-teachers' management model in online course by integrating learning support", Journal of Distance Education, vol. 5, no.10, pp.63$67, .2012$

[16] Yan Ling., "Perspective of Web-based course by analyzing question answering records", China distance education, vol.115, pp.50$52,2008$.

[17] Ye Tao., "China medical education technology. Design and realization of role and authorization in internet-based course instruction and management platform", China distance education, vol. 13, pp.36-41, 2010.

[18] Zhang Yin., "Analysis and thinking on the mechanism of answering system", China Distance Education, vol. 2, pp.11-14, 2006.

\section{AUTHOR}

Weiliang Lin is with the school of physical education and sports science of Guangzhou university, Guangzhou, China (e-mail: linweiliang70@163.com).

This work is a 2010- present campus special research program funded by Guangzhou university and a 2015 education evaluation project funded of Guangdong assessment association.

Submitted 09 October 2015. Published as submitted by the author 17 November 2015. 